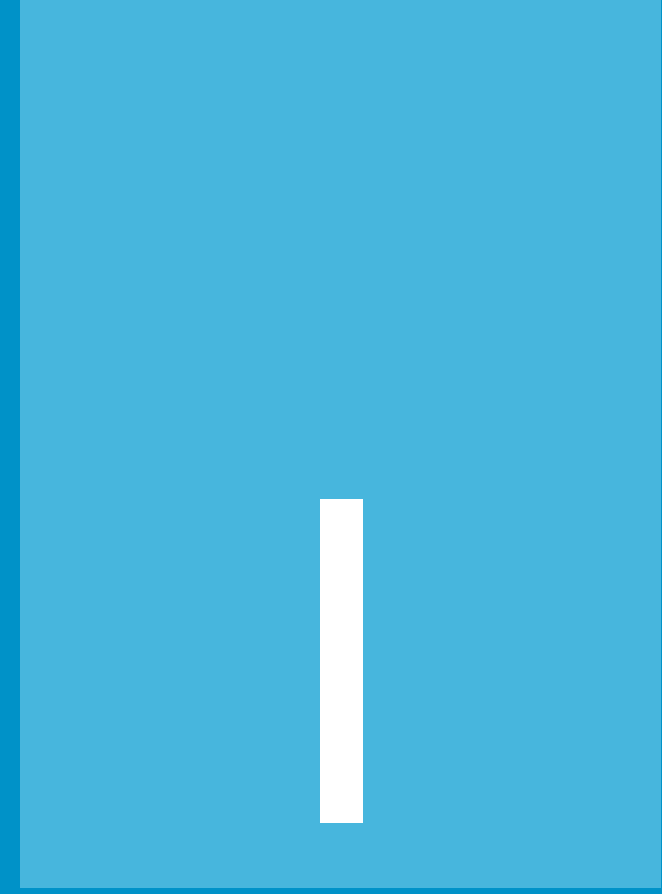

\title{
LÍDER SIERVO: UN NUEVO PARADIGMA
}

\section{Servant Leader: A New Paradigm}

\section{John Wesley Taylor V.}

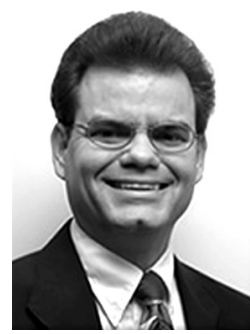

Bachiller en Administración Educativa por Andrews University. Magíster en Tecnología Educativa por la Universidad de Tennessee. Ph. D. en Currículo e Instrucción por Andrews University. Ed. D. en Psicología Educativa e Investigación por la Universidad de Virginia. Se ha desempeñado como profesor y administrador de varias instituciones, incluyendo la Universidad de Montemorelos (México), AllAS (Filipinas), Andrews University y Southern Adventist University (EE.UU.). Ha publicado numerosos artículos en revistas nacionales y extranjeras, es ponente y conferenciante a nivel nacional e internacional. Actualmente se desempeña como director asociado del sistema mundial de educación de la Iglesia Adventista del Séptimo Día. 
John Wesley Taylor V. $\quad$ AÑO II • NÚMERO 2 • p. 9 - 28

\section{Resumen}

El estilo de liderazgo que uno adopta se fundamenta en su cosmovisión, en su perspectiva de vida. La cosmovisión del samaritano, relatada por Cristo (Lucas 10:30-36), lleva a un cambio de paradigma en la vida de un líder, de un "qué puedo ganar" a un "qué puedo dar". En el presente artículo se analiza las perspectivas y dimensiones bíblicas del líder siervo. Considerando a Jesucristo como modelo perfecto del líder siervo.

Palabras clave: Liderazgo, líder siervo, toma de decisiones.

\section{Abstract}

Leadership that one adopts is based on their Worldviews and in his outlook on life. The worldview of the Samaritan told by Christ (Luke 10:30-36) and it leads to a paradigm shift in the life of a leader.In a situation "what can I win" to other "what can I give". In this article discusses the prospects and biblical proportions Servant Leader, and taking Christ as the perfect model of a servant Leader.

Keywords: Leadership, servant leader, decision-making 


\section{Introducción}

El estilo de liderazgo que uno adopta se fundamenta en su cosmovisión y en su perspectiva de vida. En la historia del buen samaritano, relatada por Cristo (LC 10:30-36), se identifican tres enfoques hacia la vida. Tenemos primeramente la perspectiva de los ladrones: Te quito lo que tienes. Tanto el sacerdote como el levita compartían otra posición: Retengo lo que tengo. Y finalmente, observamos el enfoque del samaritano: Comparto lo que tengo. De estos tres, Cristo señaló que la orientación del samaritano cumplía la relación esperada de un ser humano con su prójimo.

La cosmovisión del samaritano lleva a un cambio de paradigma en la vida de un líder, de un "qué puedo ganar" a un "qué puedo dar". Muchas veces un líder se enfoca en lo que puede recibir, sea productividad, respeto o elogio. Bajo el nuevo paradigma, el líder se apunta hacia lo que puede dar, tal como apoyo, comprensión y aliento.

En el enfoque bíblico, un liderazgo siervo incluye por lo menos tres dimensiones. En primera instancia, el líder es un siervo de Dios. En el nuevo testamento, tanto Pablo como Santiago se presentan en sus escritos como "siervo de Dios" (Tit 1:1; Stg 1:1). En el antiguo testamento, Moisés instó al pueblo de Israel: "Ahora pues, Israel, ¿̇qué pide Jehová tu Dios de ti, sino que... sirvas a Jehová tu Dios con todo tu corazón, y con toda tu alma" (Dt 10:12).

Hay una segunda dimensión. Un líder también debe ser siervo del evangelio, compartiendo con otros las nuevas de salvación. Pablo, por ejemplo, escribió: "Soy hecho siervo del evangelio por el don de la gracia de Dios que me ha sido dado" (Ef 3:7; véase también Col 1:23).

Finalmente, un líder debe ser siervo de la humanidad. El apóstol Juan señaló: "Este mandamiento tenemos de Él: que el que ama a Dios, ame también a su hermano" (1 Jn 4:21). Asimismo, Pablo recalcó: "Servíos por amor los unos a los otros" (Gá 5:13). Es notable que al iniciar su ministerio en Nazaret, Jesús marcó estas mismas tres dimensiones del líder siervo, anunciando:

El Espíritu del Señor es sobre mí. Por cuanto me ha ungido para dar buenas nuevas a los pobres; me ha enviado a sanar a los quebrantados de corazón.
[Siervo de Dios] [Siervo del evangelio]

[Siervo de la humanidad] 
John Wesley Taylor V.

A pregonar a los cautivos

libertad y a los ciegos vista,

para poner en libertad a los oprimidos. (LC 4:18,19, énfasis añadido)

En esencia, las Sagradas Escrituras afirman que un liderazgo siervo es el modelo cristiano. Pedro, por ejemplo, indica: “Cada uno deberá usar el don que ha recibido para servir a otros". (1 P 4:10), y Cristo mismo proclamó: "El que dirige debe ser como el que sirve". (Lc 22:26).

¿En qué consiste, entonces, el liderazgo siervo? ¿Qué elementos lo conforman? Hay, por lo menos, seis componentes esenciales de un líder siervo: (1) provee liderazgo, (2) comparte el liderazgo, (3) valora a las personas, (4) desarrolla a las personas, (5) forma comunidad y (6) ministra (vea la Figura 1). Consideraremos cada uno de estos factores.

Figura 1. Componentes del liderazgo siervo.

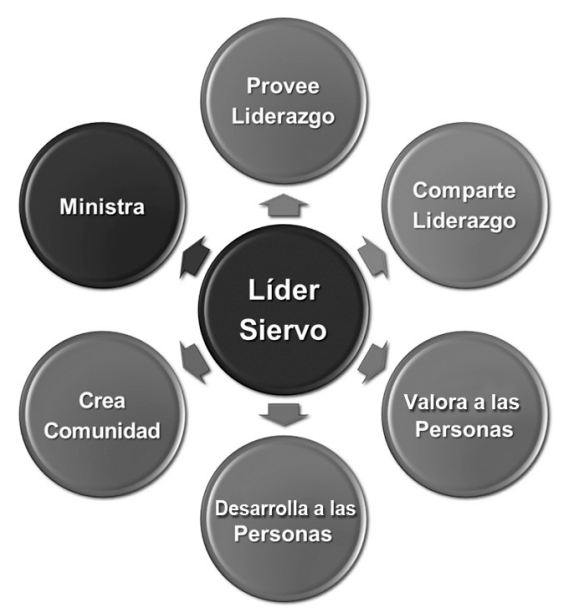

\section{Provee liderazgo}

En primera instancia, un líder siervo es un líder y, por lo tanto, deberá proveer liderazgo. Comentaremos solamente un aspecto de este liderazgo, la toma de decisiones. Supongamos que uno está en un remate y ve un artículo que le atrae. Pero no está seguro si deberá tratar de adquirirlo o no. Comienza el proceso y varias personas comienzan a ofrecer. Pero uno todavía no se 
resuelve. Finalmente, el artículo es vendido. Y después de todo, te decidiste. Lo mismo ocurre muchas veces con los que deberían ser líderes. Al no tomar decisiones en forma intencional y oportuna, lo que resulta son decisiones por defecto y una gestión sobre la base de crisis. Como dijo alguien: "A veces pienso que soy indeciso. Pero luego no estoy tan seguro".

Por supuesto, hay que pesar las evidencias y no lanzarse a decisiones precipitadas pero, al fin de cuenta, hay que tomar una decisión. ¿Cómo se puede equilibrar el aspecto de pesar evidencias con el de tomar decisiones? Se requiere desarrollar la capacidad de distinguir entre convicción y prejuicio, entre perseverancia y terquedad, entre precaución y cobardía, entre aventura y especulación, entre confianza y atrevimiento, y entre humildad y timidez.

Brunt (1979), menciona que existen entre cristianos varios modelos populares para la toma de decisiones. El primero de estos modelos se denomina: Solo obedezca. No hay que pensar o razonar. Solamente obedecer. Pero existen varios problemas con este modelo. Busca formar un comportamiento cristiano sin una mente cristiana (Ro 12:2; 1 Co 2:16; Fil 2:5). Ignora también la importancia de los motivos. A veces podemos hacer cosas aparentemente correctas pero con motivos muy egoístas. Además, existe el problema de que las Escrituras no nos proveen soluciones predefinidas para muchos dilemas morales. $Y$ aun para aquellas situaciones para las cuales tenemos orientaciones explícitas, tendemos buscar a pretextos para eludir aun los mandatos específicos.

El segundo modelo: Solo ame. La perspectiva en este modelo es que si solamente amamos suficiente, podemos hacer lo que queramos. Pero existen varias dificultades con este enfoque. En primera instancia, el amor hacia uno mismo a menudo llega a ser la forma dominante del amor. Por igual, es fácil reducir el amor a un sentimiento nebuloso que no significa nada más que hacer lo que más queremos hacer. Además, esta orientación ignora la importancia de los resultados de nuestras acciones y tendemos a olvidar que la justicia es parte integral del amor.

Un tercer modelo es aquel que proclama: Solo Jesús. Aquí lanzamos la pregunta, ¿Qué es lo que Jesús haría? Pero hay problemas con tomar esta posición. Es fácil, por ejemplo, imponer nuestros propios deseos sobre nuestro análisis de lo que Cristo haría. Por lo tanto, frecuentemente dos opiniones acerca de lo que Jesús haría en una situación dada no son iguales. En vez de conjeturar lo que Cristo pudo haber hecho, es mucho más importante descubrir los valores y principios en lo que Jesús realmente hizo y aplicarlos a nuestras vidas.

El cuarto modelo: Solo el Espíritu. Aquí frecuentemente escuchamos 
John Wesley Taylor V.

el consejo, "Solamente deje que el Espíritu te guíe". Pero, ¿cómo se distingue entre la insistencia del Espíritu y los deseos personales? ¿Es ese sueño la voz de Dios o el resultado de una cena muy pesada anoche? ¿Y cómo es que uno sabe cuál espíritu obra? "Dejar que el Espíritu nos guíe" podría ser nada más dejarse controlar por las circunstancias.

Ya que estos modelos populares resultan deficientes, ¿cuáles serían las pautas cristianas para la toma de decisiones? Aunque hay muchos factores que influyen en la toma de decisiones (vea, por ejemplo, la tabla 1), consideraremos siete principios orientadores. El concepto cardinal es el de (1) establecer un fundamento de principios y valores cristianos derivados de las Escrituras, que podrán proveer base sólida para tomar decisiones cristianamente. En forma conjunta, debemos (2) desarrollar las facultades de razonamiento otorgadas por Dios. Esto establecerá una mente juiciosa, resultando en un servicio con inteligencia.

Tabla 1. Algunos factores influyentes en la toma de decisiones

1. No busque popularidad a través de la toma de decisiones.

2. No tome decisiones cuando esté molesto o enojado.

3. No tome decisiones repentinamente. Tales decisiones no son más que conjeturas. Tome tiempo para pensar sobre el asunto. Dios puede tener otros planes.

4. No dilate. Una decisión tiene que ser hecha en algún momento.

5. Trate de ser objetivo. ¿Cuál es el verdadero problema? No se deje llevar por una ola de emoción.

6. Consulte con otros, especialmente con los que serán afectados.

7. No sea renuente a proceder por miedo de cometer error. Nadie es omnisapiente. Hay riesgo en toda decisión. Un líder debe estar dispuesto a cometer errores y sacar provecho de ellas.

8. Ya tomada la decisión, comprométase con ella y motive a otros. No vacile. Al mismo tiempo, ino sea terco si hay algo que claramente no está funcionando!

Para tomar decisiones desde una perspectiva cristiana, tenemos que (3) considerar el contexto. Es cierto que existen verdades absolutas, relevantes a todo lugar, tiempo y persona. Pero estos principios eternos deben aplicarse a la luz de un determinado momento, lugar y asunto (1 Co 8:1-11:1). Como el apóstol Pablo nos recuerda, es el espíritu de la ley que da vida (Ro 8:10). También 
debemos reconocer que (4) el motivo que impulsa la decisión es de suma importancia. Debemos preocuparnos no solamente por el qué, sino también por el por qué. Por igual, tenemos que aceptar que (5) las consecuencias de una acción son significativas, tal como nos recuerda 1 Co 8:13. La toma de decisiones cristianas nunca ocurre en un vacío, en forma aislada. Siempre hay que considerar la conexión a sus posibles resultados.

Como líderes cristianos la oración es esencial. Tenemos que (6) orar fervientemente por la iluminación del Espíritu de Dios. "Hay camino que al hombre le parece derecho, pero su fin es camino de muerte" ( $\operatorname{Pr} 14: 12)$. Finalmente, tenemos que (7) permitir que el poder de Dios transforme decisiones cristianas en una vida cristiana. "El espíritu a la verdad está dispuesto, pero la carne es débil" (Mt 26:41). En todo, debemos recordar que no tomamos nuestras decisiones para ganar mérito con Dios (Ro 5:8), sino como una expresión de nuestro amor hacia él.

Esto es una perspectiva alentadora, llevándonos como líderes a decisiones acertadas. "Los que decidan no hacer, en ningún ramo, algo que desagrade a Dios, sabrán, después de presentarle su caso, exactamente qué conducta seguir". (White, 2000; p. 622).

\section{Comparte el liderazgo}

Cuando el pueblo de Israel fue liberado por Dios de la esclavitud en Egipto, Moisés fue designado por Dios como el líder de su pueblo (Éx 3-4). Moisés, no obstante, tenía un concepto erróneo de su papel. Pensaba que todo lo tenía que hacer él mismo (Figura 2). Al llegar su suegro, Jetro, observó la situación e impartió a Moisés un consejo sabio: "Oye ahora mi voz; yo te aconsejaré, y Dios será contigo.... Inquiere tú de entre todo el pueblo varones de virtud, temerosos de Dios, varones de verdad, que aborrezcan la avaricia; y constituirás a éstos sobre ellos caporales sobre mil, sobre ciento, sobre cincuenta y sobre diez. Los cuales juzgarán al pueblo en todo tiempo; y será que todo negocio grave lo traerán a ti, y ellos juzgarán todo negocio pequeño: alivia así la carga de sobre ti, y han de llevarla ellos contigo". (Éx 18:19-23). 
John Wesley Taylor V.

Figura 2. El organigrama de Moisés, el líder

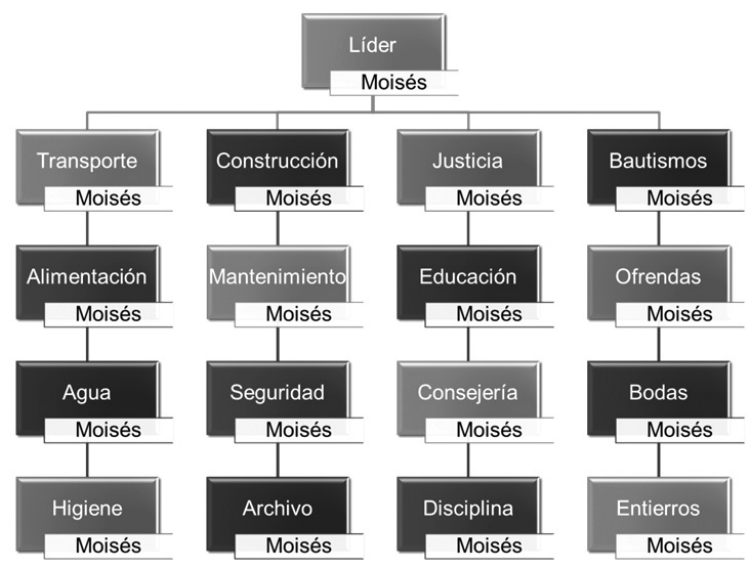

A veces tenemos el concepto de que un líder se eleva sobre un pedestal, rodeado por sus seguidores. O lo visualizamos quizás como un príncipe, cargado sobre los hombros de sus súbditos. Pero un líder siervo comparte el liderazgo. Trabaja en equipo con sus colaboradores, poniendo la pauta por su propio ejemplo.

Esto también representa un cambio de paradigma: de explotación, a edificación. En las palabras de Jesucristo: "Ya no os llamo siervos, porque el siervo no sabe lo que hace su señor. Pero os he llamado amigos". (Jn 15:15).

¿Qué es, entonces, el liderazgo compartido? Es un esfuerzo colectivo para poder lograr una visión común. No es solamente tener equipos, sino equipos empoderados. Por cierto, el liderazgo compartido requiere trabajo en equipo, pero es algo todavía más profundo, porque cada individuo bajo este paradigma ejerce liderazgo en sus propias áreas de habilidad y destreza.

Esta perspectiva del liderazgo compartido se fundamenta sobre ciertas suposiciones (Lambert, 2000). Primeramente, afirma que cada persona tiene el derecho, la responsabilidad y la habilidad de ser un líder. En segundo lugar, reconoce que empleados buscan ser más completamente de lo que son: seres humanos capaces, especialmente en sus áreas de preparación profesional y el liderazgo es un aspecto esencial de la vida profesional. Finalmente, presume que la forma cómo definimos el liderazgo influirá en la manera cómo participarán y contribuirán las personas.

Hay tres formas de ejercer el liderazgo. Un líder tiránico obliga a la acción mandando y controlando, vigilando y dominando. Un líder transaccional 
impulsa la acción por medio de la corrección y el premio, censurando y elogiando. Pero un líder transformador motiva a la acción aconsejando e inspirando. Este último representa el liderazgo compartido (vea la Figura 3).

Figura 3. Hacia un liderazgo compartido.

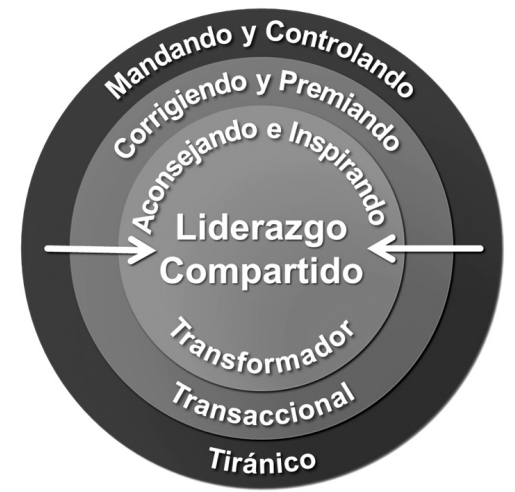

Visto de otra manera, existe una orientación opresiva que podríamos llamar el liderazgo autocrático. En ésta, el líder impone su dominio y las líneas de comunicación e influencia son unilaterales. Al contraste, el enfoque permisivo es aquel donde no se ejerce ningún elemento de liderazgo. En tal contexto "laissez faire", la organización funciona simplemente como un club social. En un liderazgo compartido, sin embargo, las vías de comunicación y de influencia son de doble sentido. El líder ve su rol como "primero entre pares", facilitando la formación y el buen funcionamiento del equipo de trabajo, de tal modo que todos ejercen sus propios elementos de liderazgo en forma coordinada (vea la Figura 4).

Figura 4. Visualización de los estilos de liderazgo autocrático, permisivo y compartido.

Liderazgo Autocrático

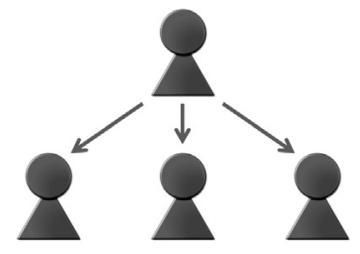


John Wesley Taylor V.

Liderazgo Laissez Faire

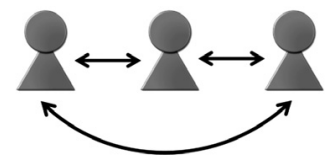

Liderazgo Compartido

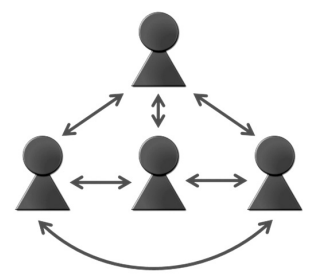

Existen dos elementos claves para alcanzar el éxito en una organización.

El primer elemento es algo denominado la moral-un sentido de ánimo, entusiasmo y convivencia entre los participantes. El segundo elemento es la productividad-el alcanzar las metas organizacionales deseadas. Un liderazgo autocrático mantiene su enfoque en la tarea, y por consecuencia alcanza un alto nivel de productividad. Pero hay un decaimiento en la moral de las personas que conforman la organización. En forma contraria, un liderazgo permisivo se enfoca casi exclusivamente en las personas y logra alcanzar un alto nivel de moral entre ellas. Pero a menudo hay poca productividad y escasos logros para la organización. ¿Cómo podemos equilibrar la moral y la productividad? Esto se logra por medio del liderazgo compartido, un liderazgo que se preocupa tanto por las metas institucionales como por el bienestar de las personas. Como resultado, la organización alcanza un alto nivel de productividad y también de moral (vea la Figura 5).

Figura 5. Alcanzando productividad y moral organizacional

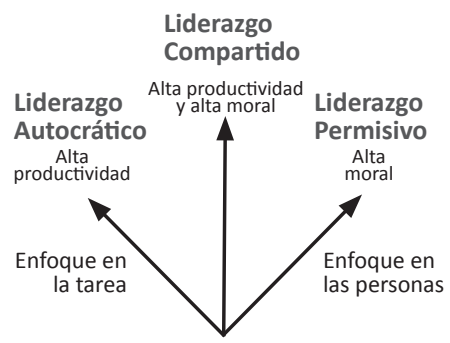


Con estos beneficios, ¿cómo podemos compartir el liderazgo? Tenemos primeramente que cultivar un entorno en el cual las personas se sientan libres para tomar la iniciativa. Tenemos también que hacer provisión para que personas calificadas tengan discreción y autonomía sobre sus tareas, recursos y animarlos a utilizar estas herramientas. Tenemos que definir claramente los parámetros que tiene cada persona para la toma de decisiones. Luego tenemos que cuidarnos de no tomar decisiones que hemos empoderado a otros para tomarlas. Pero sí tenemos que establecer reuniones de seguimiento para repasar el avance y para recalibrar cualquier asunto necesario. Finalmente, tenemos que considerar nuestro rol como líderes más en términos de un recurso que de un jefe (Sutton, 2010).

\section{Valora las personas}

En Juan 10:11-15, Cristo resaltó la diferencia en un asalariado y un buen pastor. El asalariado, señaló, trabaja para recibir recompensa, para obtener un beneficio personal. El buen pastor, sin embargo, obra por amor y se preocupa por sus ovejas. El asalariado no se interesa por las ovejas; sino que vela por sí mismo. El buen pastor discierne las necesidades de las ovejas y tiernamente cuida de ellas. El asalariado busca su propia comodidad y cuando una amenaza se levanta, abandona a las ovejas, protegiéndose a sí mismo. El buen pastor busca el bienestar de su rebaño y se arriesga por buscar una oveja perdida. El asalariado es insensible y hasta cruel con sus ovejas. El buen pastor es misericordioso y compasivo. Bajo el asalariado, las ovejas se dispersan y se destruyen y él, por el momento, se salva. Bajo el cuidado del buen pastor, las ovejas están seguras. Él, su vida da por las ovejas.

Cristo instó a sus seguidores, "Un mandamiento nuevo os doy: Que os améis unos a otros, como os he amado. En esto conocerán todos que sois mis discípulos: Si tuviereis amor los unos con los otros" (Jn 13:34-35). En el contexto popular, el "amor" se basa en la amabilidad del objeto. Nuestra preocupación, entonces, es el de ser objetos bellos y luego encontrarnos con otros objetos bellos. ¡Entonces nos felicitamos que nos hemos encontrado! En contraste, el amor ágape está basado en la capacidad de quien ama. Nuestra preocupación, entonces, es mantenernos tan cerca del amor divino que tengamos la capacidad de compartir ese mismo amor sanador con otros.

El líder siervo practica el amor ágape. Implemente la regla de oro: "Todas las cosas que quisierais que los hombres hiciesen con vosotros, así 
John Wesley Taylor V.

también haced vosotros con ellos" (Mt 5:47).

Una de las mejores formas de valorar a las personas está en formar en ellos la capacidad para el liderazgo. Hay varias maneras de desarrollar esta capacidad, especialmente en una comunidad profesional, Winn (s/f).

- Visión compartida. Al realizar alguna actividad, todo miembro de la comunidad debe continuamente preguntarse, "¿Qué conexión tiene esto con nuestra visión?" El líder tiene que tomar tiempo para contestar esta pregunta.

- Procesos distribuidos. Todo miembro de una comunidad debe participar tanto como líder, como aprendiz. Esto ocurre al formar grupos de estudio, equipos de investigación-acción y reuniones de personal enfocadas en el diálogo.

- Toma de decisiones participativas. Todo miembro de la comunidad debe examinar información para buscar respuestas y proponer nuevas preguntas. Con el apoyo del líder, los miembros de la comunidad juntos analizan, reflexionan, discuten, planifican y actúan.

- Roles y acciones colaborativas. El líder debe configurar la organización para fomentar la participación amplia, el diálogo frecuente y la responsabilidad colectiva entre los miembros de la comunidad.

- Innovación reflexiva. La reflexión permitirá que todo participante en la comunidad considere continuamente cómo podrían hacerse las cosas de manera más efectiva e innovadora. Estas ideas son valoradas por el líder.

Al valorar las personas, hay un aspecto más y tiene que ver con proveerles las herramientas necesarias para cumplir sus actividades. A veces, sin embargo, un líder cristiano cita, "Esta es la obra del Señor..." como excusa por condiciones de trabajo deficientes, miserables salarios, sobrecarga de responsabilidades o el pedido de sacrificar la familia por la organización. En realidad, el escaso apoyo se debe a la falta de un buen liderazgo. El hecho es, "Esta es la obra del Señor" y, por lo tanto, vale la pena hacerlo bien. Y esto es bíblico. Dios declaró la obra de la creación "muy bueno" (Gn 1:31); Jesús proveyó el mejor vino en las bodas de Caná (Jn 2:10); cuando los panes se multiplicaron, los discípulos fueron instruidos a recoger los fragmentos 
(Jn 6:12); y Jesús ordenó sus propios lienzos en la tumba (Jn 20:7). Todas son evidencias claras de que las cosas se deberán hacer con excelencia, especialmente hacia los que son servidos.

\section{Desarrolla las personas}

¿Cómo logramos un personal satisfecho? Empleados satisfechos son los que experimentan desarrollo continuo. Ya comentamos que un elemento cardinal de valorar a las personas se encuentra en desarrollar su capacidad de liderazgo. Miraremos ahora tres aspectos adiciones del desarrollo en una organización, en los cuales influye directamente un liderazgo siervo. Éstaos son: (1) la inducción, (2) el desarrollo profesional y (3) la supervisión.

El proceso de inducción debería incluir varios factores como proceso integrado. Entre ellos, el nuevo empleado deberá llegar a entender la visión y misión de la organización. Deberá recibir una descripción detallada del puesto, incluyendo un listado de lo que necesita saber y hacer. Deberá recibir una orientación a las políticas, procedimientos y relaciones en la organización. Deberá recibir un recorrido por las instalaciones, conociendo a personas claves. Deberá recibir un calendario de eventos importantes en la organización. Asimismo deberá haber una conversación sobre los planes para su desarrollo profesional continuo.

En primera instancia, el programa de desarrollo profesional debe enfocarse en crear un sistema colegial de mentoría, en el cual nuevos empleados son emparejados con individuos de mayor experiencia en la institución, para así darle seguimiento al proceso de inducción. El plan de desarrollo profesional, sin embargo, deberá incluir a todo empleado. Éste se forma en base a (1) materiales escritos, incluyendo manuales, guías y revistas profesionales, (2) el ofrecimiento de seminarios internos y eventos por pares, (3) la provisión de oportunidades para asistir a conferencias y talles externos, como también (4) el apoyo organizacional para la educación formal, incluyendo certificados, diplomas y posiblemente títulos avanzados. Por supuesto, un programa de desarrollo profesional también incluye momentos de autoevaluación, a veces por la preparación de un portafolio profesional, como también una retroalimentación periódica por parte de colegas. El desarrollo profesional también incluye la supervisión.

A veces tenemos una perspectiva incompleta de la supervisión. Pensamos que su propósito es únicamente promover la efectividad organizacional. Hay, sin embargo, una meta paralela y de similar importancia: 
John Wesley Taylor V.

promover el desarrollo del empleado. Como líder, entonces, no se limite a preguntar: ¿Cómo puede esta persona servir mejor a nuestra organización? Sino, también pregúntese: ¿Cómo podemos utilizar a esta persona de una manera que mejor emplee sus talentos y habilidades en forma creciente?

En un contexto educativo, por ejemplo, bien es cierto que deseamos desarrollar un programa de calidad para nuestros estudiantes. Pero esto solamente se logra si al mismo tiempo ayudamos al docente en el desarrollo de sus propias habilidades que fomentan el éxito, si les proveemos de oportunidades para definir problemas y buscar soluciones, y si establecemos un contexto en el cual cada empleado se siente aceptado y vinculado.

Incorporar esta segunda dimensión representa un cambio de paradigma: de ver la supervisión en términos de "poder sobre" el empleado, con sus reacciones típicas de hostilidad abierta o acatamiento a regañadientes, a considerar la supervisión como un asunto de "poder con" el empleado, que resulta en una cooperación dispuesta. Esta nueva orientación influye tanto en lo que hacemos antes y después de la supervisión, como durante el mismo evento.

Antes de una sesión de supervisión, necesitamos haber formado una relación de confianza y de compromiso mutuo. Esto se hace por medio de una carta de bienvenida al nuevo empleado, por medio de llamadas telefónicas ocasionales, visitas informales y comunicaciones personalizadas, y, sobre todo, por una disposición a escuchar al empleado. Al hablar con el empleado sobre el proceso de supervisión, el empleado debe llegar a estar convencido de que será beneficiado por esa observación y el análisis de su trabajo. Esto lo logramos comunicando que la supervisión es de apoyo, más que de escrutinio; que es formativo, más que sumativo; y que lo que más deseamos cultivar en él o ella es un liderazgo emergente. En total, el supervisor debe transmitir que está para ayudar, que está dispuesto a ayudar y que es capaz de ayudar.

Para la sesión de supervisión, el líder debe seleccionar un buen momento para la visita. De preferencia, deberá ocurrirse temprano en el día, y no el último día de labor semanal, o el día inmediatamente antes o después de un período de vacaciones. Anticipe pasar al menos una hora de observación y una hora de conversación. Durante la observación, vea tanto como sea posible, pero tan discretamente como sea posible.

Para un docente, por ejemplo, el supervisor puede buscar evidencias de: (a) una buena planificación, (b) el dominio de conocimiento y habilidades, tanto de su disciplina como pedagógicos, (c) un manejo eficaz del aula, (d) el involucramiento de los alumnos en el aprendizaje, (e) el uso eficiente del tiempo de clase y (f) su efectividad de los procesos de evaluación. Para ello, 
deberá concéntrese en los estudiantes, y no solo en lo que el maestro está haciendo. Deberá identificar tendencias en la enseñanza, en lugar de centrarse en casos aislados. Y, sobre todo, nunca deberá el supervisor lazarse a intervenir o hacerse cargo de la clase.

Después de una sesión de supervisión, siempre debe haber una conversación. Este diálogo debe ocurrir en un lugar tranquilo y privado. En esta reunión enfatice los aspectos positivos y haga solamente unas pocas sugerencias para mejoras, destacando las técnicas o los recursos que puedan ayudar. Apoye y comparta, en lugar de demandar y obligar. Y siempre termine con algún punto positivo. Después de esta conversación formal, manténgase en contacto. Fortifique la relación al transmitir su disponibilidad para consulta. Envíe materiales de apoyo, haga llamadas y remite correos electrónicos alentadores. Todo esto hace de la supervisión un proceso de desarrollo de la persona.

\section{Crea comunidad}

Un líder siervo crea comunidad. ¿Cómo puedes formar comunidad? Pablo escribió acerca del "cuerpo de Cristo" (Ro 12:5; 1 Co 12:12-27), de la comunidad de fe. En esta comunidad, sin embargo, hay tensión. Por un lado, hay quienes enfocan su lealtad a principios inmutables. Por el otro, hay quienes se regocijan en su libertad para cambiar y crecer. Los primeros se aferran al pasado y ven todo cambio como pecado. Los otros tienen desdén del pasado y se obsesionan con el cambio.

Cuando hay inseguridad y falta de información, la comunidad comienza a polarizarse y corre riesgo de fraccionarse. El problema mayor es que hay falta de consideración por el cuerpo de Cristo, por mantener la comunidad. El cuerpo de Cristo se preserva, sin embargo, cuando tenemos una comunidad de confianza, segura e informada, que puede distinguir entre verdad eterna y tradición, entre crecimiento requerido versus novedad, y que, sobre todo, se preocupa por mantener íntegro el cuerpo de Cristo como comunidad de fe.

Así lo enfatizó Pablo, "Con toda humildad y mansedumbre, con paciencia soportando los unos a los otros en amor; solícitos a guardar la unidad del Espíritu en el vínculo de la paz. Un cuerpo, y un Espíritu; como sois también llamados a una misma esperanza de vuestra vocación" (Efesios 4:2-4).

¿Pero qué de la libertad? En una banda u orquesta existen tres libertades. Tenemos la libertad del músico a tocar su instrumento de manera profesional, con cierto estilo, y no simplemente de manera mecánica. Pero esta 
John Wesley Taylor V.

libertad tiene que tomar en cuenta una segunda libertad y es la del conductor del conjunto, indica a todos cuándo deben comenzar y terminar, y cómo deberán como grupo interpretar la obra. Hay que reconocer, sin embargo, que existe una tercera libertad y es la del compositor de la obra, la cual espera que esta sea ejecutada dentro del marco y la intención de quien creó la obra.

De manera similar, en una organización educativa, por ejemplo, tenemos tres grandes libertades: (1) la libertad del alumno para aprender, (2) la libertad del docente para enseñar y (3) la libertad de la institución para cumplir su misión. Todas estas libertades deberán trabajar en armonía.

Hay un aspecto más que influye sobre la comunidad y tiene que ver con la evaluación. Entre los miembros de una organización tiene que ocurrir la evaluación, tanto para el bien de la organización como de los mismos miembros. La forma, sin embargo, en la cual transmitimos estos mensajes evaluativos determina su resultado final.

Una comunicación no solamente involucra el mensaje en sí, sino también al que envía el mensaje, como quien lo recibe. La persona que envía un mensaje evaluativo siempre tiene un motivo, y el mensaje evaluativo siempre tiene un efecto en quien lo recibe. Hay dos tipos de mensajes evaluativos: mensajes positivos, que llamamos elogios, y mensajes negativos, los reproches.

Un elogio puede tomar una de dos formas, dependiendo de la motivación de quien trasmite el mensaje. Cuando el motivo es egoísta: "Consigo lo mío", el mensaje es un halago, una adulación. El resultado es un orgullo humano inflado o un cinismo, cuando el que recibe el mensaje se da cuenta que no es sincero, sino que trae su agenda oculta. Si el motivo, sin embargo, es el amor: "Te aprecio", el mensaje es un estímulo y su resultado es un valor propio legítimo y la gloria para Dios.

Un reproche puede también tomar una de dos formas, dependiendo de la motivación de quien envía el mensaje. Cuando la motivación es egoísta: "Soy más santo", el mensaje evaluativo toma la forma de una crítica, de un ataque. El resultado es el desánimo o la rebelión. Pero cuando el motivo es el amor: "Te quiero mucho", el mensaje es un comunicado de preocupación y el resultado es sanidad y restauración (vea la Tabla 2 ). 
Tabla 2. Mensajes evaluativos

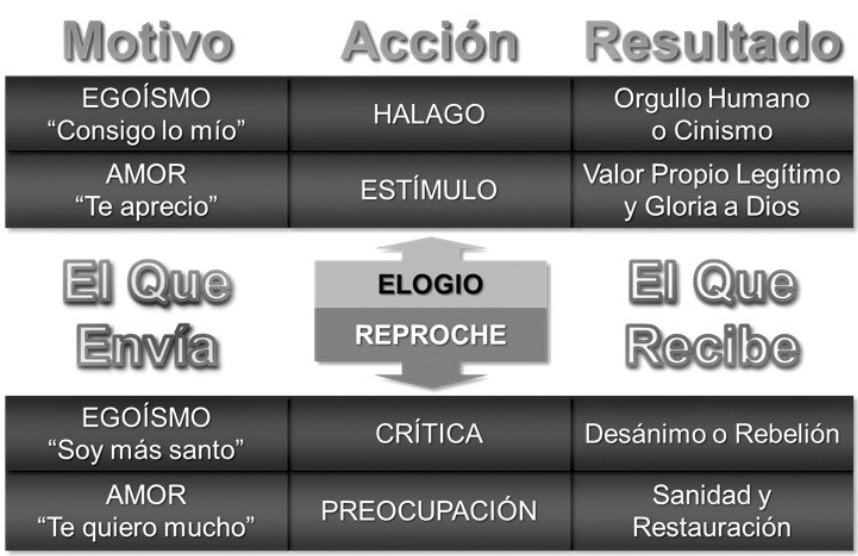

Observe que la diferencia se encuentra en el espíritu del líder, sea un espíritu de poderío o de servicio.

\section{Ministra}

En Mateo 20 encontramos la historia de la madre de Juan y Santiago, quien junto con sus hijos vino a Jesús y pidió "que en tu reino estos dos hijos míos se sienten uno a tu derecha y el otro a tu izquierda" (vrs. 21). En respuesta, Cristo clarificó que el sentarse en puestos preferenciales "no es mío el concederlo, sino que es para quienes han sido preparados por mi Padre" (vrs. 23). Los otros diez discípulos, sin embargo, escucharon del asunto y se indignaron contra Juan y Santiago. Jesús tuvo que llamarlos a todos y les dijo, "Sabéis que los gobernantes de los gentiles se enseñorean de ellos, y que los grandes ejercen autoridad sobre ellos. No ha de ser así entre vosotros. Sino que el que quiera entre vosotros llegar a ser grande, será vuestro servidor, y el que quiera entre vosotros ser el primero, será vuestro siervo. Así como el Hijo del Hombre no vino para ser servido, sino para servir y para dar su vida en rescate por muchos" (vrs. 25-27).

¿El punto clave? Un líder siervo ministra. Camina en las huellas de Cristo, quien vino para servir. He aquí siete principios del líder que ministra:

1. Un líder siervo sigue a Jesús en lugar de buscar una posición. (Mr 10:32-40) 
John Wesley Taylor V.

2. Un líder siervo se humilla a sí mismo y espera hasta que Dios lo exalte. (Lc 14:7-11)

3. Un líder siervo toma sobre sí el manto del servicio abnegado para saciar las necesidades de los demás. (Jn 13:4-11)

4. Un líder siervo está listo a renunciar a sus propios derechos para mejor proteger los derechos de los otros. (Mr 10:41-45)

5. Un líder siervo puede arriesgarse sirviendo a los demás porque confía en que Dios está en el control de su vida. (Jn 13:3)

6. Un líder siervo comparte su responsabilidad y autoridad con los demás para así alcanzar metas compartidas. (Hch 6:1-6)

7. El líder siervo multiplica su liderazgo mediante la potenciación de liderazgo en los demás. (Éx 18:17-23)

La palabra "administrar" se compone de dos partes: "ad" y "ministrar". El prefijo "ad" significa "hacia", y la raíz "ministrar" significa "servir" (vea la Figura 6). Un administrador, entonces, es alguien quien enfoca su vida en servir.

Figura 6. Administrar es servir

\section{Administrar}

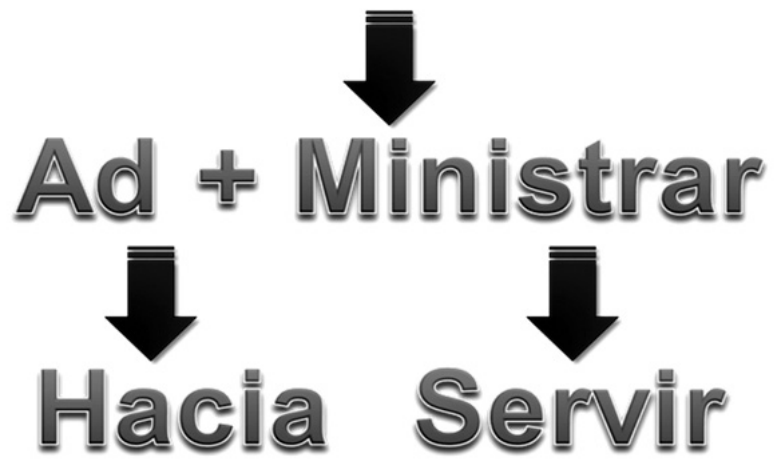




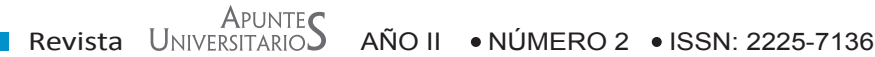

\section{Conclusión}

En síntesis, el paradigma del líder siervo se describe en las palabras del apóstol Pablo:

"Nada hagáis por egoísmo o por vanagloria, sino que con actitud humilde cada uno de vosotros considere al otro como más importante que a sí mismo, no buscando cada uno sus propios intereses, sino más bien los intereses de los demás. Haya, pues, en vosotros esta actitud que hubo también en Cristo Jesús, el cual, aunque existía en forma de Dios, no consideró el ser igual a Dios como algo a qué aferrarse, sino que se despojó a sí mismo tomando forma de siervo." (Fil 2:3-7)

Le dirijo a Jesucristo, modelo perfecto del líder siervo.

John Wesley Taylor V. Associate Director of Education email: taylorjw@gc.adventist.org

Recibido: 15 de Agosto de 2012 Aceptado: 25 de Octubre de 2012 
John Wesley Taylor V.

\section{Referencias}

Brunt, J. (1979). Decisions: How to use biblical guidelines when making decisions. Nashville: Southern Publishing.

Lambert, L. (2002). A framework for shared leadership. Educational Leadership, mayo, 2002.

Sutton, R. (2010). Sharing leadership to maximize talent. Paragon Strategies.

Online: http://paragonstrategies

White, E. (2000). El deseado de todas las gentes. Miami: Publicaciones Interamericanas.

Winn, R. (s/f). Seminario de relaciones humanas. 